\title{
Diagnosed hypertension in Canada: incidence, prevalence and associated mortality
}

\author{
Cynthia Robitaille MSc, Sulan Dai MD PhD, Chris Waters BSc, Lidia Loukine MSc, Christina Bancej PhD, \\ Susan Quach MSc, Joellyn Ellison MPH, Norman Campbell MD, Karen Tu MD MSc, Kim Reimer BEd BSc, \\ Robin Walker MSc, Mark Smith MSc, Claudia Blais PhD, Hude Quan MD PhD
}

\section{Abstract}

Background: Hypertension is a leading risk factor for cardiovascular diseases. Our objectives were to examine the prevalence and incidence of diagnosed hypertension in Canada and compare mortality among people with and without diagnosed hypertension.

Methods: We obtained data from linked health administrative databases from each province and territory for adults aged 20 years and older. We used a validated case definition to identify people with hypertension diagnosed between 1998/99 and 2007/08. We excluded pregnant women from the analysis.

Results: This retrospective population-based study included more than 26 million people. In 2007/08, about 6 million adults (23.0\%) were living with diagnosed hypertension and about 418000 had a new diagnosis. The agestandardized prevalence increased signifi- cantly from $12.5 \%$ in $1998 / 99$ to $19.6 \%$ in 2007/08, and the incidence decreased from 2.7 to 2.4 per 100 . Among people aged 60 years and older, the prevalence was higher among women than among men, as was the incidence among people aged 75 years and older. The prevalence and incidence were highest in the Atlantic region. For all age groups, allcause mortality was higher among adults with diagnosed hypertension than among those without diagnosed hypertension.

Interpretation: The overall prevalence of diag nosed hypertension in Canada from 1998 to 2008 was high and increasing, whereas the incidence declined during the same period. These findings highlight the need to continue monitoring the effectiveness of efforts for managing hypertension and to enhance public health programs aimed at preventing hypertension.
Competing interests: None declared. Susan Quach's contribution to the manuscript was made in her previous capacity at the Public Health Agency of Canada. No official support or endorsement by Public Health Ontario is intended, nor should be inferred.

This article has been peer reviewed.

Correspondence to:

C. Robitaille,

cynthia.robitaille@phac-aspc .gc.ca

CMAJ 2012. DOI:10.1503 /cmaj.101863
$\mathrm{G}$ lobally, raised blood pressure is the leading risk factor for death, accounting for about $13 \%$ of all deaths, ${ }^{1,2}$ and it is the strongest risk factor for lost years of healthy life. ${ }^{1}$ Left untreated, hypertension can increase the risk of stroke, coronary artery disease, dementia, heart and kidney failure, and other chronic diseases..$^{3-6}$ Managing hypertension through lifestyle modification or the use of antihypertensive medications, or both, can help mitigate these outcomes. ${ }^{7}$ Over the past decades in Canada, mortality associated with cardiovascular diseases has decreased, ${ }^{8}$ partly because of increased awareness and diagnosis of hypertension and better control of blood pressure. ${ }^{9,10}$ However, the prevalence of hypertension remains high, and currently there are no mechanisms to track new cases at the national level.

To date, information about hypertension in Canada has been mainly obtained by health surveys conducted at the provincial or national levels. Such surveys typically provide prevalence (not incidence) data and include limited data about trends over time. ${ }^{11-15}$ National health surveys in Canada are resource intensive, do not include information about people who live in remote areas or institutions, and may underestimate hypertension prevalence because of recall bias and nonresponse ${ }^{16}$ The use of administrative data that is population-based and routinely collected, such as physician claims and hospital discharge data, allows for a more comprehensive picture of this condition. Other important advantages of using administrative data include the readiness of the data to be analyzed, cost-efficiency, wide geographic coverage and the relatively complete capture of patient contact with the health care system (i.e., less prone to selection bias).

Several recent studies in Canada and the United States have established valid methods for using administrative data to identify cases of hypertension. ${ }^{16-23}$ In a study conducted in Ontario involving women and men aged 20 years and older, Tu and colleagues found that the prevalence and incidence of diagnosed hypertension were $24.5 \%$ in 2005 and $3.2 \%$ in 2004 , respectively. ${ }^{24}$ We used the same 
validated case definition to examine the prevalence and incidence of diagnosed hypertension in Canada from $1998 / 99$ to $2007 / 08$ by age and by province and territory. We also compared all-cause mortality by age and sex among those with and without diagnosed hypertension.

\section{Methods}

\section{Study design}

We performed a retrospective population-based cohort study involving Canadian adults aged 20 years and older from 1998/99 to 2007/08. There is usually a lag time of two to three years for jurisdictions to obtain data and to accrue evidence for the application of the case definition for diagnosed hypertension. Although data from the provinces and territories were collected beginning in 1995/96, we chose $1998 / 99$ as the starting point to exclude records of patients who had received a diagnosis of hypertension before the study period. This allowed us to avoid overestimating the number of incident cases. We chose 2007/08 as the end point because it had the most recent data available at the start of the study.

\section{Data sources}

The Canadian Chronic Disease Surveillance System is a collaborative network of provincial and territorial surveillance systems supported by the Public Health Agency of Canada. This network collects and reports surveillance information on diagnosed diabetes (formerly the National Diabetes Surveillance System) ${ }^{25}$ and other chronic conditions, such as diagnosed hypertension. ${ }^{26}$ The Canadian Chronic Disease Surveillance System collects aggregated data by use of a personal health insurance number from linked administra- tive databases from each province and territory, namely the health insurance registry, physician billing and hospital discharge databases. All provinces and territories use a standardized set of SAS macros to process their data, which ensures comparability. Full-time members of the Canadian Forces and people in the Royal Canadian Mounted Police and federal correctional facilities are not included in these databases.

We obtained data on age, sex, place of residence and date of death from health insurance registries, except in Quebec. We used the census to obtain this information for the province of Quebec. We used the total number of people eligible for health insurance in a province or territory, or the insured population, as the denominator for determining incidence, prevalence and mortality.

The physician billing database includes all fee-for-service payments for services rendered and may include information about alternate payment structures using shadow-billing claims. Many provinces and territories also include nurse-practitioner claims. Each claim contains at least one diagnosis coded using the ninth revision of the International Classification of Diseases (ICD), except in the province of New Brunswick where no standard nomenclature is used. Instead, they searched for the term "hypertension" and its abbreviations and acronyms.

Demographic, administrative and clinical data for all patients discharged from a hospital were obtained through the Canadian Institute for Health Information's Discharge Abstract Database for most provinces and territories and from the MedÉcho system for Quebec. Up to 16 diagnoses, including the most responsible diagnosis, are listed for each hospital discharge when ICD-9 is used and up to 26 diagnoses when ICD-10 is used.

\begin{tabular}{|c|c|c|c|c|c|c|}
\hline \multirow[b]{2}{*}{ Year } & \multicolumn{3}{|c|}{ Prevalence, \% } & \multicolumn{3}{|c|}{ Incidence, per 100 per year } \\
\hline & Women & Men & Total & Women & Men & Total \\
\hline 1998/99 & 13.2 & 11.7 & 12.5 & 2.9 & 2.5 & 2.7 \\
\hline $1999 / 00$ & 14.4 & 12.9 & 13.8 & 2.8 & 2.5 & 2.7 \\
\hline $2000 / 01$ & 15.6 & 14.1 & 14.9 & 2.9 & 2.7 & 2.8 \\
\hline $2001 / 02$ & 16.5 & 15.2 & 16.0 & 2.8 & 2.6 & 2.7 \\
\hline $2002 / 03$ & 17.4 & 16.2 & 16.8 & 2.8 & 2.6 & 2.7 \\
\hline $2003 / 04$ & 18.1 & 17.0 & 17.6 & 2.7 & 2.6 & 2.7 \\
\hline $2004 / 05$ & 18.7 & 17.7 & 18.2 & 2.6 & 2.6 & 2.6 \\
\hline $2005 / 06$ & 19.1 & 18.4 & 18.8 & 2.5 & 2.6 & 2.6 \\
\hline $2006 / 07$ & 19.5 & 18.9 & 19.3 & 2.4 & 2.6 & 2.5 \\
\hline $2007 / 08$ & 19.7 & 19.4 & 19.6 & 2.3 & 2.4 & 2.4 \\
\hline
\end{tabular}




\section{Hypertension case definition}

We considered insured individuals aged 20 years and older to have diagnosed hypertension if they met the following criteria: either two or more physician claims for hypertension within two years, or one recording of hypertension in the hospital discharge abstract. We identified hypertension cases using the relevant ICD codes (ICD9-CM: 401.x, 402.x, 403.x, 404.x or 405.x; ICD10-CA: I10.x, I11.x, I12.x, I13.x or I15.x). Once the case definition was met, prevalent cases remained prevalent while the patients were alive and resided in the province or territory (as long as their health insurance number was valid). Cases were deemed incident in the first year in which they met the case definition, and cases could be considered incident only once. Before 2001, all provinces and territories used the ICD9 or ICD-9-CM classification system for both hospital discharge and physician billing data. For discharge data, however, some jurisdictions began using the ICD-10-CA classification in 2001/02 and some began using it by 2006/07. Validation studies conducted in three Canadian provinces showed that the sensitivity of the case definition was $66 \%-72 \%$, the specificity was $95 \%-97 \%$, the positive predictive value was $77 \%-87 \%$ and the negative predictive value was $88 \%-93 \% .^{17-19,24}$

To exclude cases of gestational hypertension, we excluded women aged 20-54 years with suspected pregnancy-induced hypertension (defined as a diagnosis code for hypertension 120 days before or 180 days after any pregnancy-related visit). Specific diagnosis codes indicative of pregnancy or obstetric events are available in the National Diabetes Surveillance System methods documentation. ${ }^{27}$

\section{Statistical analysis}

Statistical analyses were performed using SAS Enterprise Guide (version 4.1). We calculated prevalence by dividing the total number of people diagnosed with hypertension by the insured population (or by the census population for Quebec). We calculated projected prevalence counts for five years (2008/09 to 2012/13) based on conservative assumptions in which we presumed that age- and sex-specific hypertension incidence and mortality would remain constant for the duration of the five-year projection period. We then applied these rates to moderate growth population projections by province and territory and summed the values to give the projected number of prevalent hypertension cases. We calculated incidence by dividing the total number of people with newly diagnosed hypertension during the selected fiscal year by the total number of people at risk for hypertension during the same year (total number of insured population minus the prevalent cases). We obtained mortality rate ratios by dividing all-cause mortality among people with diagnosed hypertension by that among people without diagnosed hypertension.

Where indicated, the incidence and prevalence were age-standardized to the 1991 Canadian population aged 20 years and older to allow a comparison of hypertension rates over the study period, and we calculated $95 \%$ confidence intervals (CIs). We conducted linear regression on the log of the rates to estimate the average annual per cent change. We evaluated statistical significance by testing the slope parameter for being different from zero. We used $t$ tests to compare rates across jurisdictions and by sex.

\section{Results}

In 2007/08, about 6 million (23.0\%) Canadian adults had diagnosed hypertension. The crude prevalence was higher among women $(24.3 \%$, $95 \%$ CI $24.2 \%-24.3 \%$ ) than among men (21.7\%, 95\% CI 21.7\%-21.8\%).

About 418000 adults had newly diagnosed hypertension in 2007/08. The crude incidence per 100 was higher among men $(2.1,95 \%$ CI 2.1-2.1) than among women $(1.9,95 \%$ CI 1.9-2.0).

Overall, the age-standardized prevalence of diagnosed hypertension increased from $12.5 \%$ in $1998 / 99$ to $19.6 \%$ in $2007 / 08$, with an average annual change of $5 \%(p<0.001$; Table 1 , Figure $1)$. The average annual per cent change was not

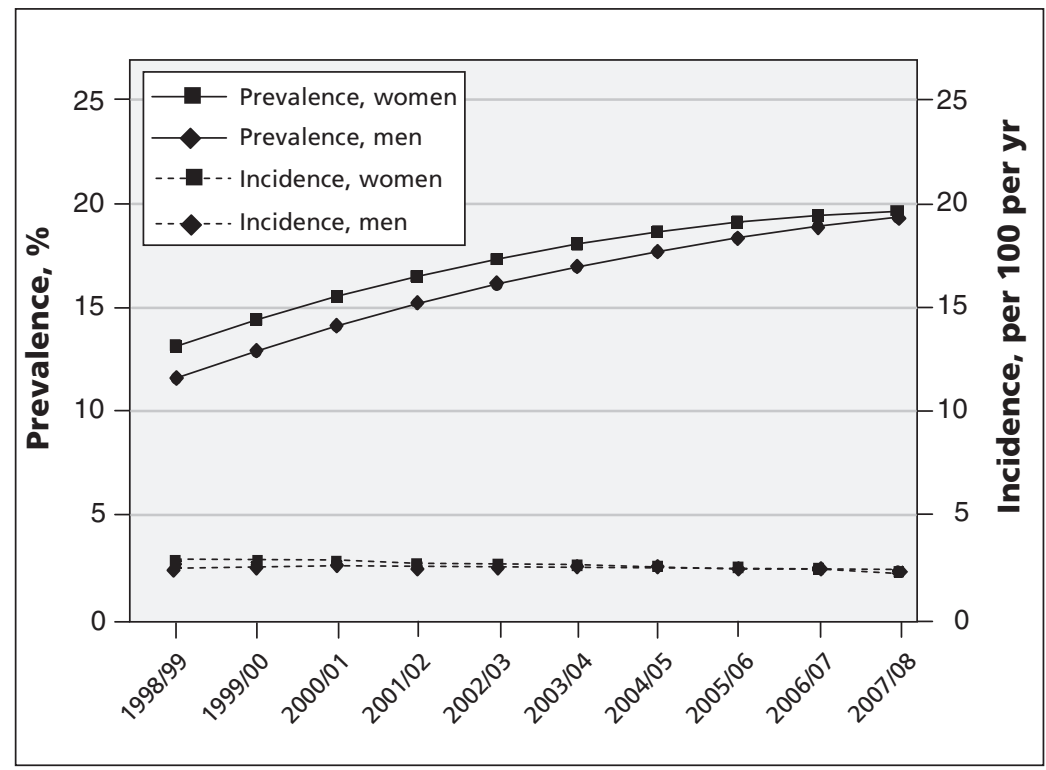

Figure 1: Prevalence and incidence of diagnosed hypertension among adults aged 20 years and older from 1998/99 to 2007/08 in Canada. The rates have been age-standardized to the 1991 Canadian population. 
significantly different between women and men ( $p=0.06)$. In contrast, the age-standardized incidence remained stable throughout the study period among men, with an average rate of $2.6 \%$. There was a significant decrease in the average annual percent change of $2 \%$ among women $(p<0.001$; Figure 1 , Table 1$)$. If the 2007/08 age- and sex-specific incidence and mortality remain constant, we forecast that about $26.5 \%$ (7.4 million) of Canadian adults will be living with diagnosed hypertension by 2012/13 (Figure 2).

The prevalence of diagnosed hypertension increased with increasing age. The incidence also increased with age, up to age 80-84 (Figure $3)$. The prevalence was similar among women

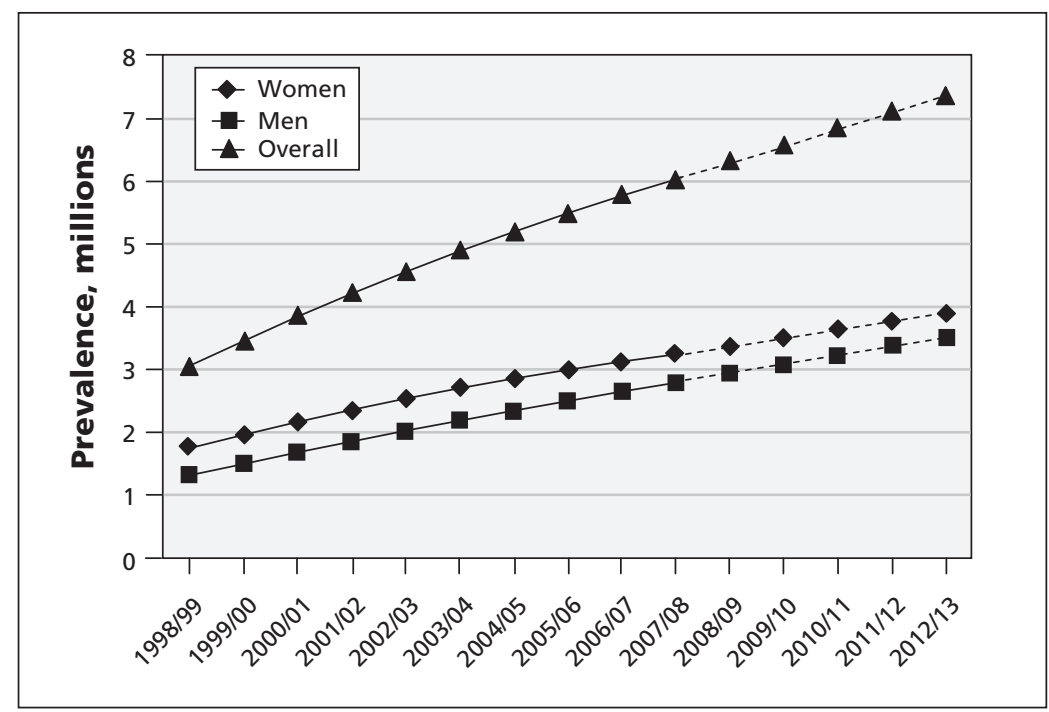

Figure 2: Observed and projected number of prevalent cases of hypertension among adults aged 20 years and older, by sex. Observed: 1998/99 to 2007/08; projected: $2008 / 09$ to $2012 / 13$.

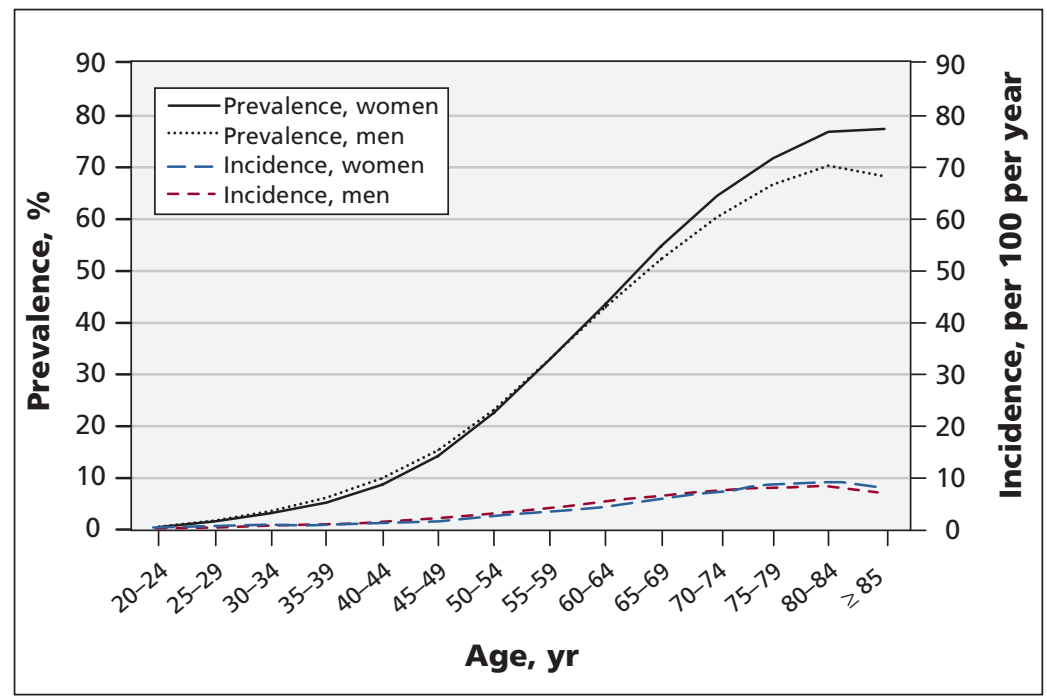

Figure 3: Age-specific prevalence and incidence of diagnosed hypertension among adults aged 20 years and older in 2007/08, by sex. and men under age 60. From the age 60 onwards, the prevalence was higher among women than among men. For example, among those aged 60-64 years, the prevalence was $43.6 \%$ (95\% CI 43.5\%-43.7\%) among women and $43.0 \%$ (95\% CI 42.9\%-43.2\%) among men. Similarly, the incidence was higher among women than among men for those aged 75 years or more. For example, the incidence per 100 was 8.6 (95\% CI 8.5-8.8) among women aged 75-79 years, while it was 8.2 (95\% CI 8.0-8.3) among men of a similar age (Table 2).

The age-standardized prevalence of diagnosed hypertension was higher in the Atlantic region $(23.3 \%)$ than in the territories and western Canada (19.0\%) $(p<0.001$; Figure 4, Table 3). A similar pattern was observed for incidence, with an age-standardized incidence per 100 of 3.3 in the Atlantic region and 2.5 in the territories and western Canada combined ( $p<0.001$; Figure 4).

All-cause mortality increased with increasing age and was consistently higher among people of all ages with hypertension (2.2-120.4 per 1000) than among those without hypertension $(0.5-$ 105.1 per 1000) ( $p<0.05$; Figure 5, Table 4$)$. Mortality was two to four times higher among adults aged 20-49 years with hypertension than among those without hypertension $(p<0.05)$. In contrast, mortality was 1.1-1.8 times higher among adults aged 50 years and older with hypertension than among those without hypertension $(p<0.05)$.

\section{Interpretation}

In this population-based study involving more than 26 million adults in Canada, we found that the age-standardized prevalence increased significantly from $12.5 \%$ in $1998 / 99$ to $19.6 \%$ in 2007/08. The incidence per 100 during the same period decreased from 2.7 to 2.4 .

Overall, the crude prevalence of diagnosed hypertension $(23.0 \%$ ) reported in 2007/08 was higher than that reported in the 2007 Canadian Community Health Survey $(19.2 \%) .{ }^{28}$ Self-reported hypertension in the latter survey may have been lower because about $5 \%$ of people who report the use of medication for hypertension do not report having hypertension, possibly because they think that they do not have the condition or that their hypertension has been "cured" when their blood pressure is controlled by medication or lifestyle modification. ${ }^{29}$ Similarly, the crude prevalence observed in our study is higher than the prevalence based on direct blood pressure measurements among people aged 20-79 years in the Canadian Health Measures Survey (19.4\%). ${ }^{11}$ The prevalence of hypertension may also have been lower in those 
two surveys because they sampled only the household population, whereas our data were for all Canadian adults (with the previously noted exceptions) who have used the health care system.

The increase in the number of people with diagnosed hypertension is similar to that observed in studies conducted in Ontario and Manitoba using the same validated case definition. ${ }^{18,24}$ However, the population prevalence of hypertension estimated from health measure surveys was stable between 1992 and 2009, varying only between $19.7 \%$ and $21.6 \% .^{30}$ The increase observed in our study may be partly because more people are being screened and diagnosed by physicians, and thus more people are aware of their condition. ${ }^{11,13,30,31}$ The proportion of Canadians with hypertension who are aware of their condition increased from $56.9 \%$ in 1992 to $82.5 \%$ in 2009 . Another likely contributor to this rise is the decline in mortality among people with hypertension and other cardiovascular diseases. ${ }^{8,932}$ A recent systematic review using health examination survey data from 199 countries and territories found that, globally, systolic blood pressure decreased by $1 \mathrm{~mm} \mathrm{Hg}$ per decade for men and

\begin{tabular}{|c|c|c|c|c|c|c|}
\hline \multirow[b]{2}{*}{ Age, yr } & \multicolumn{3}{|c|}{ Prevalence, \% } & \multicolumn{3}{|c|}{ Incidence, per 100 per year } \\
\hline & Women & Men & Total & Women & Men & Total \\
\hline $20-24$ & 0.5 & 0.6 & 0.5 & 0.2 & 0.2 & 0.2 \\
\hline $25-29$ & 1.6 & 1.7 & 1.6 & 0.3 & 0.3 & 0.3 \\
\hline $30-34$ & 3.2 & 3.6 & 3.4 & 0.4 & 0.6 & 0.5 \\
\hline $35-39$ & 5.2 & 6.2 & 5.7 & 0.7 & 0.9 & 0.8 \\
\hline $40-44$ & 8.7 & 9.9 & 9.3 & 1.2 & 1.4 & 1.3 \\
\hline $45-49$ & 14.2 & 15.4 & 14.8 & 1.9 & 2.1 & 2.0 \\
\hline $50-54$ & 22.6 & 23.1 & 22.8 & 2.7 & 3.0 & 2.8 \\
\hline $55-59$ & 32.8 & 32.9 & 32.9 & 3.4 & 4.0 & 3.7 \\
\hline $60-64$ & 43.6 & 43.0 & 43.3 & 4.6 & 5.2 & 4.9 \\
\hline $65-69$ & 54.8 & 52.3 & 53.6 & 6.1 & 6.4 & 6.3 \\
\hline $70-74$ & 64.5 & 60.4 & 62.6 & 7.5 & 7.4 & 7.4 \\
\hline $75-79$ & 71.8 & 66.7 & 69.5 & 8.6 & 8.2 & 8.4 \\
\hline $80-84$ & 77.0 & 70.3 & 74.3 & 9.2 & 8.4 & 8.8 \\
\hline$\geq 85$ & 77.5 & 68.3 & 74.6 & 7.6 & 6.9 & 7.3 \\
\hline
\end{tabular}

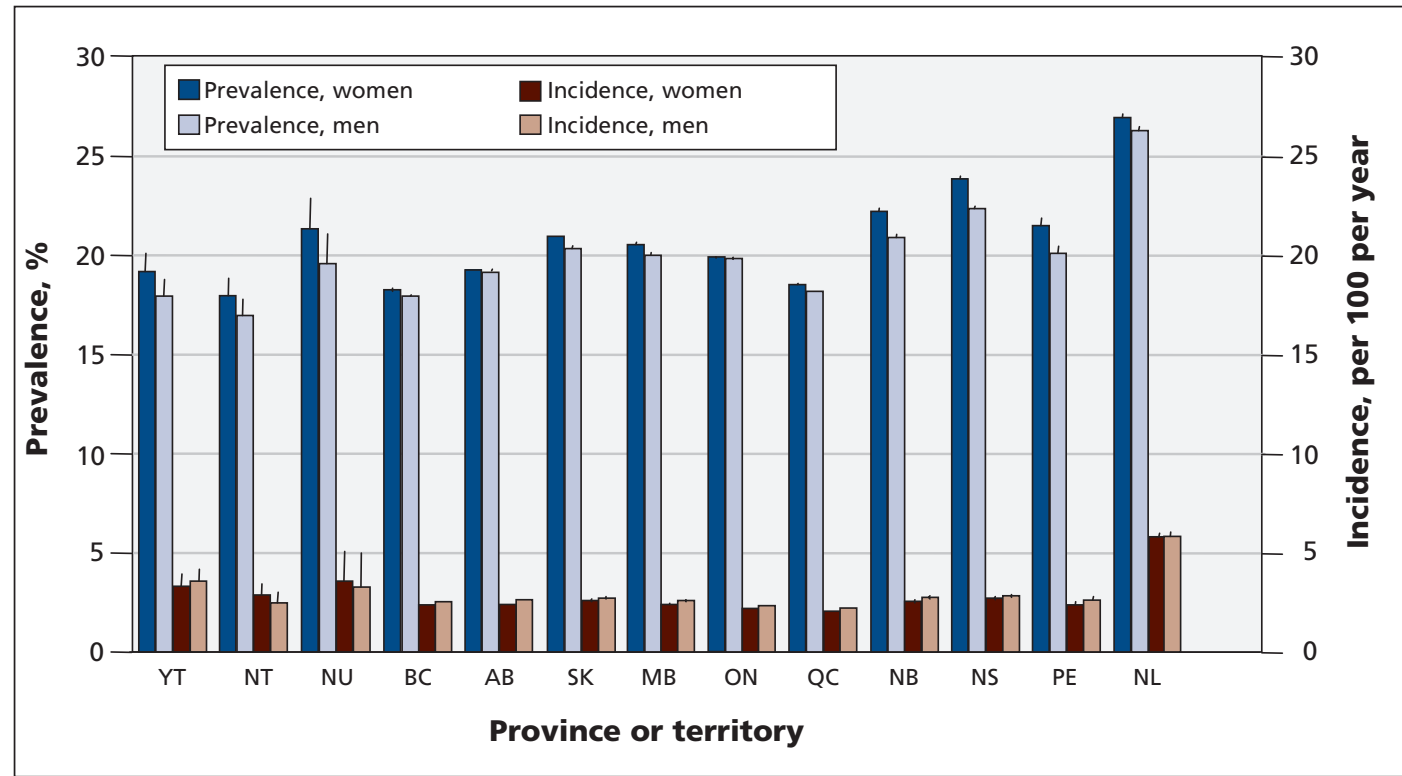

Figure 4: Prevalence and incidence of diagnosed hypertension among people aged 20 years and older in 2007/08, by sex and province or territory. Rates are age-standardized to the 1991 Canadian population. Error bars indicate $95 \%$ confidence intervals. 
women between 1980 and $2008 .^{33}$ Country- and region-specific data, however, showed complex patterns, with some modest to large decreases in systolic blood pressure in many areas but with some steady trends in others and possible increases in certain regions. These results may differ from the overall pattern in our study because those studies relied on direct blood pressure measurements, thus identifying individuals with hypertension who may not have been aware of their condition, while we relied on diagnosed hypertension.

The modest decrease we observed in the incidence of diagnosed hypertension may be because

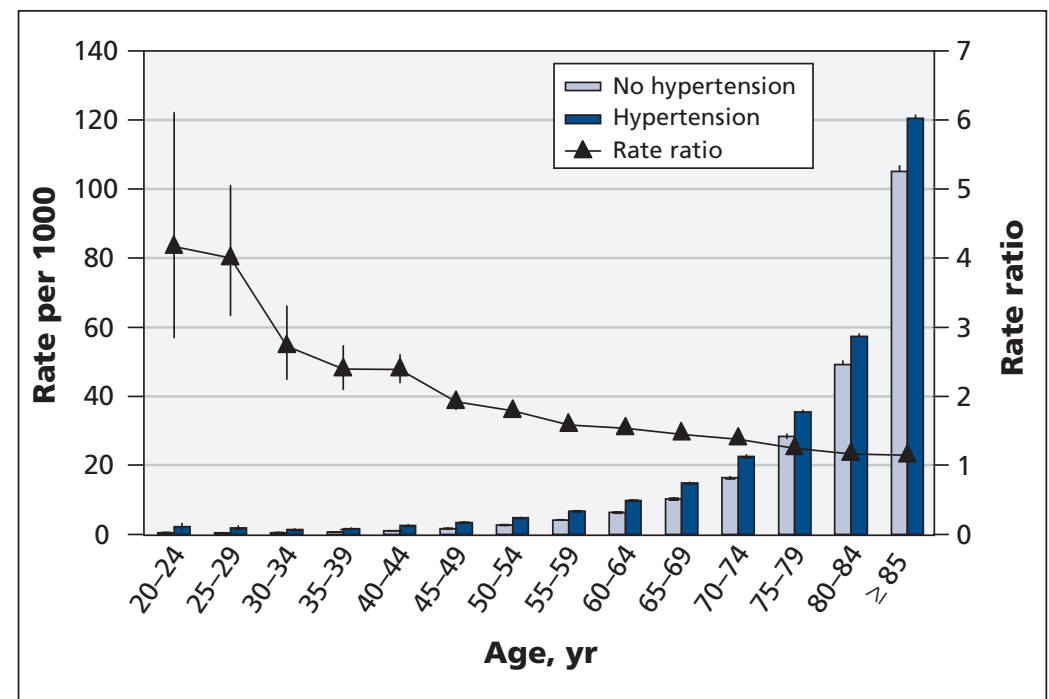

Figure 5: All-cause annual mortality and rate ratios in 2007/08 among adults aged 20 years and older with and without diagnosed hypertension, by age. Error bars indicate $\mathbf{9 5 \%}$ confidence intervals. of the variation in trends in cardiovascular risk factors over the past decades in Canada. Although obesity rates have increased, ${ }^{34}$ leisure time, physical inactivity and smoking rates have decreased. ${ }^{35-}$ ${ }^{37}$ Nonetheless, evidence from this study indicates that increased preventive measures are warranted to see a continued decrease in incident cases in the short term and a decrease in prevalence in the longer term.

In this study, prevalence increased with increasing age, whereas incidence increased up to age $80-84$ years. The age-specific prevalence and incidence indicate that elderly women have higher rates of diagnosed hypertension than elderly men. This may be explained by the fact that women are, in general, more aware of hypertension than men, as shown in other studies..$^{31,38-41}$

We found important regional variations, with higher prevalence and incidence observed in the Atlantic region than in the territories and western Canada. This pattern is consistent with the eastto-west gradients reported in other Canadian studies of risk factors, namely obesity and diabetes. ${ }^{42,43}$ In addition, this pattern follows the east-to-west gradient of cardiovascular health outcomes, such as heart disease, for which hypertension is a leading risk factor. ${ }^{44}$

All-cause mortality was higher among people with hypertension than among those without hypertension, with rate ratios ranging between 1.9 and 4.2 among younger people. This may indicate that people with diagnosed hypertension, especially younger adults, are less healthy than those without diagnosed hypertension and thus experience worse

Table 3: Age-standardized* prevalence and incidence of diagnosed hypertension among adults aged 20 years and older in $2007 / 08$, by province or territory.

\begin{tabular}{|c|c|c|c|c|c|c|}
\hline \multirow[b]{2}{*}{ Province or territory } & \multicolumn{3}{|c|}{ Prevalence, \% } & \multicolumn{3}{|c|}{ Incidence, per 100 per year } \\
\hline & Women & Men & Total & Women & Men & Total \\
\hline British Columbia & 18.3 & 17.9 & 18.1 & 2.4 & 2.5 & 2.4 \\
\hline Alberta & 19.3 & 19.1 & 19.3 & 2.4 & 2.6 & 2.5 \\
\hline Saskatchewan & 21.0 & 20.4 & 20.7 & 2.6 & 2.7 & 2.7 \\
\hline Manitoba & 20.5 & 20.0 & 20.3 & 2.4 & 2.6 & 2.5 \\
\hline Ontario & 19.9 & 19.9 & 19.9 & 2.2 & 2.3 & 2.3 \\
\hline Quebec & 18.5 & 18.2 & 18.5 & 2.1 & 2.2 & 2.2 \\
\hline New Brunswick & 22.2 & 20.9 & 21.6 & 2.6 & 2.7 & 2.7 \\
\hline Nova Scotia & 23.9 & 22.3 & 23.2 & 2.7 & 2.8 & 2.8 \\
\hline Prince Edward Island & 21.5 & 20.1 & 20.9 & 2.4 & 2.6 & 2.5 \\
\hline $\begin{array}{l}\text { Newfoundland and } \\
\text { Labrador }\end{array}$ & 27.0 & 26.3 & 26.6 & 5.8 & 5.9 & 5.8 \\
\hline Yukon Territory & 19.2 & 17.9 & 18.5 & 3.3 & 3.6 & 3.5 \\
\hline Northwest Territories & 18.0 & 17.0 & 17.5 & 2.9 & 2.5 & 2.7 \\
\hline Nunavut & 21.4 & 19.6 & 20.4 & 3.5 & 3.3 & 3.5 \\
\hline
\end{tabular}


health outcomes. However, because we did not investigate cause of death, we cannot attribute mortality specifically to cardiovascular disease. In addition, the confidence intervals for the rate ratios in the younger groups are wide (Figure 5), and the results need to be interpreted with caution.

\section{Limitations}

The findings of this study should be considered in light of the following limitations. First, only people who were in contact with the health care system and who received a diagnosis of hypertension were included in this study. About $17 \%$ of Canadian adults with measured hypertension are unaware of their condition. ${ }^{11}$ Thus, our estimates of prevalence and incidence are likely underestimated. ${ }^{11}$ This probably did not have a large impact on our results, however, because a large proportion of Canadians (almost 80\%) responding to the 2001 Canadian Community Health Survey reported that they had at least one contact with a general practitioner in the past 12 months ${ }^{45}$ As well, population denominators derived from administrative data have been shown to be comparable to those calculated using the Canadian census, with a difference of less than $1 \% .^{46}$

Second, the use of health administrative data to estimate diagnosed hypertension can result in the misclassification of hypertension cases and noncases. Thus, balancing false-negatives and falsepositives is required. Validation studies have indicated that the case criteria used by the Canadian

Table 4: All-cause mortality and rate ratios among adults aged 20 years and older with and without diagnosed hypertension in Canada in 2007/08

\begin{tabular}{|lccc|}
\hline \multicolumn{4}{|c|}{$\begin{array}{c}\text { All-cause mortality, } \\
\text { per 1000 people }\end{array}$} \\
\cline { 2 - 3 } Age, yr & No hypertension Hypertension & $\begin{array}{c}\text { Rate } \\
\text { ratio }\end{array}$ \\
\hline $20-24$ & 0.5 & 2.2 & 4.2 \\
\hline $25-29$ & 0.5 & 2.0 & 4.0 \\
\hline $30-34$ & 0.5 & 1.5 & 2.7 \\
\hline $35-39$ & 0.7 & 1.8 & 2.4 \\
\hline $40-44$ & 1.1 & 2.6 & 2.4 \\
\hline $45-49$ & 1.8 & 3.5 & 1.9 \\
\hline $50-54$ & 2.7 & 4.9 & 1.8 \\
\hline $55-59$ & 4.2 & 6.7 & 1.6 \\
\hline $60-64$ & 6.4 & 9.8 & 1.5 \\
\hline $65-69$ & 10.3 & 14.9 & 1.5 \\
\hline $70-74$ & 16.5 & 22.7 & 1.4 \\
\hline $75-79$ & 28.5 & 35.5 & 1.2 \\
\hline $80-84$ & 49.2 & 57.4 & 1.2 \\
\hline$\geq 85$ & 105.1 & 120.4 & 1.1 \\
\hline
\end{tabular}

Chronic Disease Surveillance System minimizes both false-negatives and false-positives. . $^{17-19,47}$ However, the case definition we used to identify cases maximizes specificity (95\%-97\%) compared with sensitivity $(66 \%-72 \%)$, which would thus underestimate the proportion of Canadians diagnosed with hypertension. ${ }^{18,1924}$

Third, geographic differences cannot be explained with certainty. Provincial and territorial coding practices and the capture of billing information from salaried physicians may differ by jurisdiction. However, because the validity of the case definition was similar among Ontario, Manitoba, Alberta and British Columbia, ${ }^{17-19}$ it is more likely that patterns of risk factors, rather than methodologic limitations, explain the variation.

\section{Conclusion}

The number of people living with diagnosed hypertension has increased steadily from 1998/99 to 2007/8. In addition, almost half a million Canadians were newly diagnosed with hypertension in 2007/08 alone, and the incidence only slightly declined during the study period. Programs to improve the lifestyles of Canadians, such as the proposed initiative to reduce sodium consumption, ${ }^{48}$ will be critical to decrease the incidence and prevalence of diagnosed hypertension in Canada. This study highlights the need to continue tracking diagnosed hypertension in Canada to provide timely surveillance information that can be used to enhance prevention and management programs for Canadians.

\section{References}

1. World Health Organization. Global health risks: mortality and burden of disease attributable to selected major risks. Geneva (Switzerland): The Organization; 2009. p. 1-62.

2. World Health Organization. The world health report 2002: reducing risks, promoting healthy life. Geneva (Switzerland): The Organization; 2002. p. 248.

3. MacMahon S, Peto R, Cutler J, et al. Blood pressure, stroke, and coronary heart disease. Part 1 , prolonged differences in blood pressure: prospective observational studies corrected for the regression dilution bias. Lancet 1990;335:765-74.

4. Duron E, Hanon O. Hypertension, cognitive decline and dementia. Arch Cardiovasc Dis 2008;101:181-9.

5. Jafar TH, Stark PC, Schmid CH, et al. Progression of chronic kidney disease: the role of blood pressure control, proteinuria, and angiotensin-converting enzyme inhibition: a patient-level meta-analysis. Ann Intern Med 2003;139:244-52.

6. Tozawa M, Iseki $\mathrm{K}$, Iseki $\mathrm{C}$, et al. Blood pressure predicts risk of developing end-stage renal disease in men and women. Hypertension 2003;41:1341-5.

7. Hackam DG, Khan NA, Hemmelgarn BR, et al. The 2010 Canadian Hypertension Education Program recommendations for the management of hypertension: part 2 - therapy. Can J Cardiol 2010;26:249-58.

8. Manuel DG, Leung M, Nguyen K, et al.; Canadian Cardiovascular Outcomes Research Team. Burden of cardiovascular disease in Canada. Can J Cardiol 2003;19:997-1004.

9. Campbell NR, Brant R, Johansen H, et al. Increases in antihypertensive prescriptions and reductions in cardiovascular events in Canada. Hypertension 2009;53:128-34.

10. McAlister FA, Feldman RD, Wyard K, et al.; CHEP Outcomes Research Task Force. The impact of the Canadian Hypertension Education Programme in its first decade. Eur Heart J 2009;30: 1434-9. 
11. Wilkins K, Campbell NR, Joffres MR, et al. Blood pressure in Canadian adults. Health Reports 2010;21.1-11.

12. Leenen FH, Dumais J, McInnis NH, et al. Results of the Ontario survey on the prevalence and control of hypertension. CMAJ 2008; 178:1441-9.

13. Joffres MR, Ghadirian P, Fodor JG, et al. Awareness, treatment, and control of hypertension in Canada. Am J Hypertens 1997; 10:1097-102.

14. Lee DS, Chiu M, Manuel DG, et al. Trends in risk factors for cardiovascular disease in Canada: temporal, socio-demographic and geographic factors. CMAJ 2009;181:E55-66.

15. Wolf HK, Andreou P, Bata IR, et al. Trends in the prevalence and treatment of hypertension in Halifax County from 1985 to 1995. CMAJ 1999;161:699-704.

16. Muhajarine N, Mustard C, Roos LL, et al. Comparison of survey and physician claims data for detecting hypertension. J Clin Epidemiol 1997;50:711-8.

17. Tu K, Campbell NR, Chen ZL, et al. Accuracy of administrative databases in identifying patients with hypertension. Open Med 2007; 1:e18-e26.

18. Lix L, Yogendran M, Burchill C, et al. Hypertension. In: Defining and validating chronic diseases: an administrative data approach. Winnipeg (MB): Manitoba Centre for Health Policy; 2006. p. 93.

19. Quan H, Khan N, Hemmelgarn BR, et al. Validation of a case definition to define hypertension using administrative data Hypertension 2009;54:1423-8.

20. Rector TS, Wickstrom SL, Shah M, et al. Specificity and sensitivity of claims-based algorithms for identifying members of Medicare+Choice health plans that have chronic medical conditions. Health Serv Res 2004;39:1839-57.

21. Quam L, Ellis LB, Venus P, et al. Using claims data for epidemiologic research. The concordance of claims-based criteria with the medical record and patient survey for identifying a hypertensive population. Med Care 1993;31:498-507.

22. Robinson JR, Young TK, Roos LL, et al. Estimating the burden of disease. Comparing administrative data and self-reports. Med Care 1997;35:932-47.

23. Wilchesky M, Tamblyn RM, Huang A. Validation of diagnostic codes within medical services claims. J Clin Epidemiol 2004;57: 131-41

24. Tu K, Chen Z, Lipscombe LL; Canadian Hypertension Education Program Outcomes Research Taskforce. Prevalence and incidence of hypertension from 1995 to 2005: a populationbased study. CMAJ 2008;178:1429-35.

25. Public Health Agency of Canada. National Diabetes Surveillance System. Ottawa (ON): The Agency; 2010. Available: www.ndss. gc.ca (accessed 2011 July 5).

26. Public Health Agency of Canada. Report from the Canadian Chronic Disease Surveillance System: hypertension in Canada, 2010. Ottawa (ON): The Agency; 2011. Available: www.phacaspc.gc.ca/cd-mc/cvd-mcv/ccdss-snsmc-2010/index-eng.php (accessed 2011 July 5).

27. Public Health Agency of Canada. National diabetes surveillance system methods documentation, 2008. Ottawa (ON): The Agency; 2009; Available: www.phac-aspc.gc.ca/ccdpc-cpcmc /ndss-snsd/english/diabetes_data/00-06/pdf/method_v208-eng.pdf (accessed 2011 July 5)

28. Public Health Agency of Canada. Tracking heart disease and stroke in Canada. Ottawa (ON): The Agency; 2009. p. 118.

29. Gentleman JF, Tomiak M. The consistency of various high blood pressure indicators based on questionnaire and physical measures data from the Canada Health Survey. Health Rep 1992;4:293-311.

30. McAlister FA, Wilkins K, Joffres M, et al. Changes in the rates of awareness, treatment and control of hypertension in Canada over the past two decades. CMAJ 2011;183:1007-13.

31. Onysko J, Maxwell C, Eliasziw M, et al. Large increases in hypertension diagnosis and treatment in Canada after a healthcare professional education program. Hypertension 2006;48:853-60.

32. Tu K, Chen Z, Lipscombe LL; Canadian Hypertension Education Program Outcomes Research Taskforce. Mortality among patients with hypertension from 1995 to 2005: a populationbased study. CMAJ 2008;178:1436-40.

33. Danaei G, Finucane MM, Lin JK, et al. National, regional, and global trends in systolic blood pressure since 1980: systematic analysis of health examination surveys and epidemiological studies with 786 country-years and 5.4 million participants. Lancet 2011;377:568-77.

34. Katzmarzyk PT, Mason C. Prevalence of class I, II and III obesity in Canada. CMAJ 2006; 174:156-7.

35. Katzmarzyk PT, Tremblay MS. Limitations of Canada's physical activity data: implications for monitoring trends. Can J Public Health 2007;98(Suppl 2):S185-94

36. Stephens M, Siroonian J. Smoking prevalence, quit attempts and successes. Health Rep 1998;9:31-7.
37. Shields M. The journey to quitting smoking. Health Rep 2005; 16:19-36.

38. Kearney PM, Whelton M, Reynolds K, et al. Global burden of hypertension: analysis of worldwide data. Lancet 2005;365:217-23.

39. Kastarinen M, Antikainen R, Peltonen M, et al. Prevalence, awareness and treatment of hypertension in Finland during 1982-2007. J Hypertens 2009;27:1552-9.

40. Falaschetti E, Chaudhury M, Mindell J, et al. Continued improvement in hypertension management in England: results from the Health Survey for England 2006. Hypertension 2009;53:480-6.

41. Danon-Hersch N, Marques-Vidal P, Bovet P, et al. Prevalence, awareness, treatment and control of high blood pressure in a Swiss city general population: the CoLaus study. Eur J Cardiovasc Prev Rehabil 2009;16:66-72.

42. Public Health Agency of Canada. Obesity in Canada - snapshot. Ottawa (ON): The Agency; 2011. Available: www.phac-aspc .gc.ca/publicat/2009/oc/index-eng.php (accessed 2011 July 5).

43. Public Health Agency of Canada. Report from the National Diabetes Surveillance System: diabetes in Canada, 2009. Ottawa (ON): The Agency; 2009. Available: www.phac-aspc.gc.ca/publicat /2009/ndssdic-snsddac-09/index-eng.php (accessed 2011 July 5).

44. Chow CM, Donovan L, Manuel D, et al.; Canadian Cardiovascular Outcomes Research Team. Regional variation in self-reported heart disease prevalence in Canada. Can J Cardiol 2005;21:1265-71.

45. Quan H, Fong A, De Coster C, et al. Variation in health services utilization among ethnic populations. CMAJ 2006;174:787-91.

46. Comparison of Alberta population counts between the AHCIP Registry and the 2006 census. Edmonton (AB): Alberta Health and Wellness; 2009; Available: www.health.alberta.ca/documents /Population-2006-Comparison-2009.pdf (accessed 2010 Sept. 14).

47. Quan H, Li B, Duncan Saunders L, et al. Assessing validity of ICD-9-CM and ICD-10 administrative data in recording clinica conditions in a unique dually coded database. Health Serv Res 2008;43:1424-41

48. Sodium reduction strategy for Canada, recommendations of the Sodium Working Group. Ottawa (ON): Health Canada; 2010. Available: www.hc-sc.gc.ca/fn-an/nutrition/sodium/strateg/index -eng.php (accessed 2010 Sept. 10).

Affiliations: From the Chronic Disease Surveillance and Monitoring Division (Robitaille, Dai, Waters, Loukine, Bancej, Ellison), Public Health Agency of Canada, Ottawa, Ont.; Public Health Ontario (Quach), Toronto, Ont.; the University of Calgary (Campbell, Walker, Quan), Calgary, Alta.; the Institute for Clinical Evaluative Sciences (Tu), Toronto, Ont.; the British Columbia Ministry of Health Services (Reimer), Victoria, BC; the Manitoba Centre for Health Policy (Smith), Winnipeg, Man.; and the Institut national de santé publique du Québec and Faculté de pharmacie, Université Laval (Blais), Québec, Que.

Contributors: All of the authors contributed to the conception and design of the study and interpreted the data. Cynthia Robitaille drafted the manuscript. Chris Waters, Joellyn Ellison, Christina Bancej, Mark Smith, Kim Reimer, Karen Tu and Claudia Blais were involved in the acquisition of data. Cynthia Robitaille, Chris Waters, Lidia Loukine and Susan Quach performed the statistical analyses. All of the authors critically revised the manuscript for important intellectual content and approved the final version submitted for publication.

Acknowledgements: The Canadian Chronic Disease Surveillance System (CCDSS) is a collaborative project between the Public Health Agency of Canada and the provinces and territories. The members of the CCDSS Science Committee, the CCDSS Technical Working Group and the Public Health Network Task Group on the Surveillance of Chronic Disease and Injury have contributed to the development of the system. The authors are grateful to the Hypertension Outcomes and Surveillance Team for their contribution to the validation of the case definition of hypertension.

The Institute for Clinical Evaluative Sciences is funded by an annual grant from the Ontario Ministry of Health and Long-Term Care. The opinions, results and conclusions reported in this paper are those of the authors and are independent from the funding sources. No endorsement by Institute for Clinical Evaluative Sciences or the Ontario Ministry of Health and Long-Term Care is intended or should be inferred. 